\title{
Comparison of Ginsenoside and Phenolic Ingredient Contents in Hydroponically-cultivated Ginseng Leaves, Fruits, and Roots
}

\author{
Sang Yoon Choi", Chang-Won Cho, Yeonmi Lee, Sung Soo Kim, Sang Hee Lee, and Kyung-Tack Kim \\ Korea Food Research Institute, Seongnam 463-746, Korea
}

In this study, hydroponically-cultivated ginseng leaves, fruits, and roots were respectively extracted with ethanol. The contents of 12 ginsenosides and three phenolics in the extracts were quantitatively analyzed and the free radical scavenging activities were measured and compared. Hydroponically-cultivated ginseng leaves contained higher levels of gensenosides (Rg1, Rg2+Rh1, Rd, and $\operatorname{Rg} 3$ ) and $p$-coumaric acid than the other parts of the ginseng plants. The 2,2'-azino-di-(3-ethylbenzothiazoline)-6-sulfonic acid radical scavenging activities of leaves were also the highest. Accordingly, hydroponically-grown ginseng leaves were shown to hold promise for use as an environmentally-friendly natural anti-oxidant.

Keywords: Panax ginseng, Hydroponic cultivation, Leaves, Ginsenoside, Phenolic compound

\section{INTRODUCTION}

Ginseng plants, Panax ginseng are cultivated in soil for 4 to $6 \mathrm{yr}$, and ginseng roots are mostly used as medicine and food, whereas all other parts of the plant are discarded. More recently, non-pesticides and hydroponically-grown ginseng leaves have been used in salads. Thus, there is a need to study the active ingredients in hydroponically-grown ginseng plants. There have been many studies on the ingredient contents of ginseng plants grown in soil [1-4]; however, very little research has been conducted on the ingredient contents and antioxidative activities of hydroponically-grown ginseng plants. Accordingly, in this study, hydroponically-cultivated ginseng leaves, fruits and roots were separated and the contents of 12 ginsenosides and three phenolics were quantitatively analyzed. In addition, the free radical scavenging activities of the extracts were measured and compared.

\section{MATERIALS AND METHODS}

\section{Materials}

For this study, hydroponically-grown ginseng plants were purchased in May 2011 from the Hydroponic Ginseng Agricultural Union Corporation located in Seocheon-gun, Chungcheongnam-do Province, Korea. The corporation cultivated 1- to 2-year-old ginseng plants for $120 \mathrm{~d}$ with a hydroponic cultivation system without using pesticides until the plants grew to a weight of 5 to $20 \mathrm{~g}$.

\section{Production of extract specimens}

Whole ginseng plants were cleansed with distilled water. Then the leaves, fruits, and roots of the plants were separated and heat air-dried at $50^{\circ} \mathrm{C}$ for $36 \mathrm{~h}$. The dried plants were then ground to powder. Each powder specimen was mixed with ethanol and extracted three times. The obtained supernatants were filtered and concentrated in vacuum to produce extract specimens. (c) This is an Open Access article distributed under the terms of the Creative Commons Attribution Non-Commercial License (http://creativecommons.org/licenses/by-nc/3.0/) which permits unrestricted non-commercial use, distribution, and reproduction in any medium, provided the original work is properly cited.
Received 02 May. 2012, Revised 17 May. 2012, Accepted 03 Jul. 2012

*Corresponding author

E-mail: sychoi@kfri.re.kr

Tel: +82-31-780-9307, Fax: +82-2-31-709-9876 
A

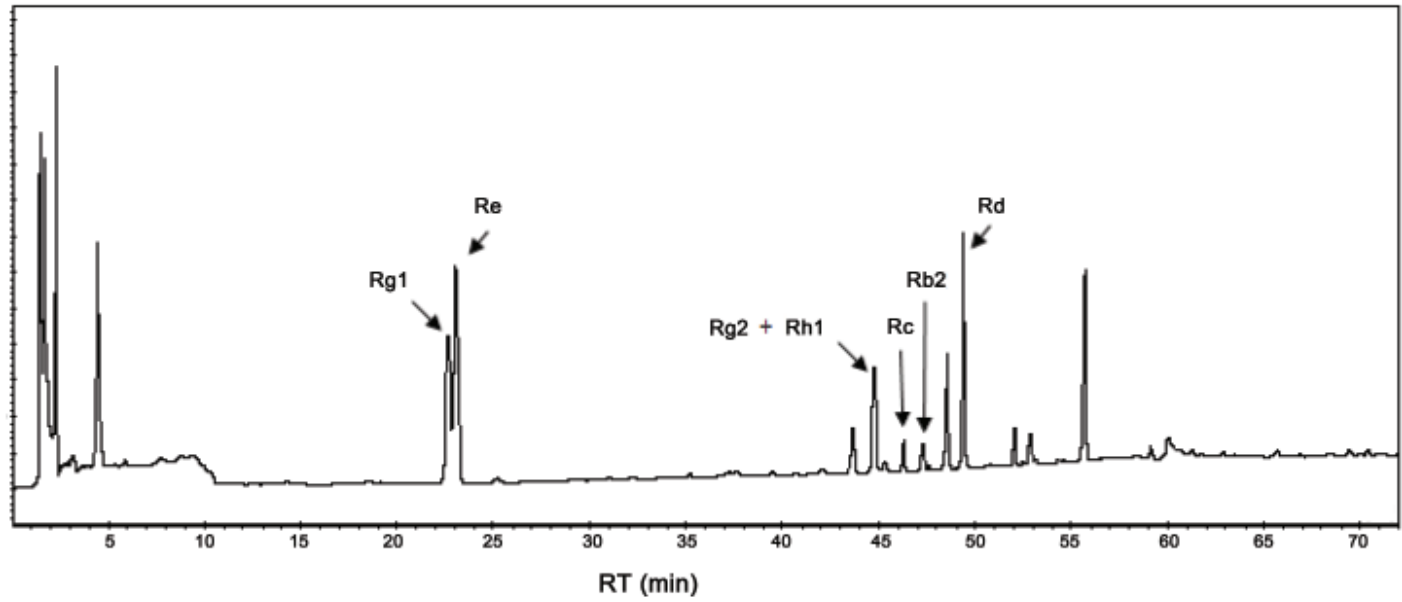

B

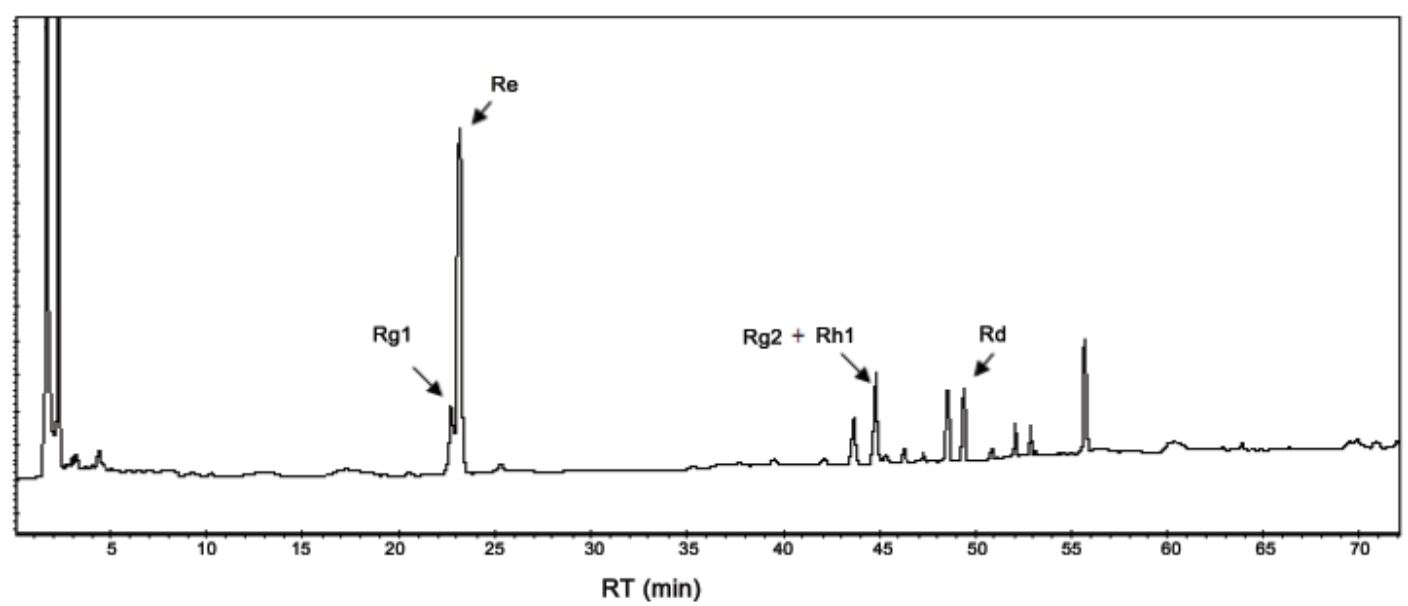

C

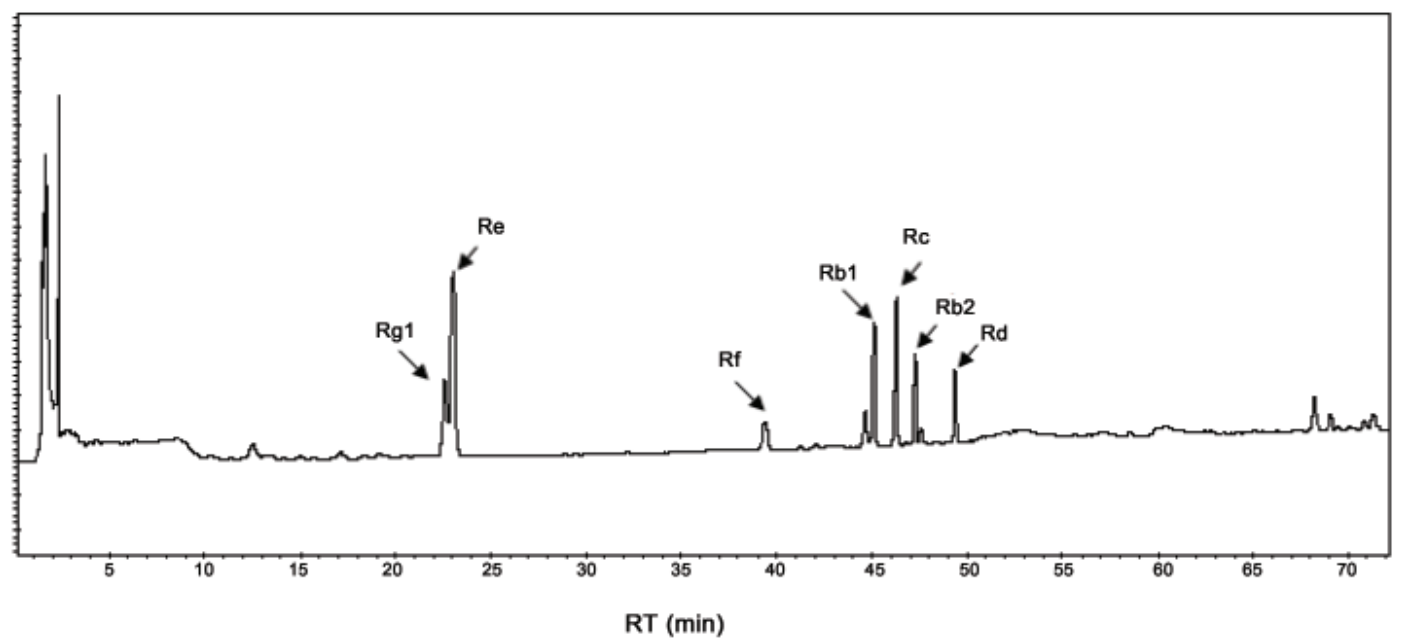

Fig. 1. Chromatogram of ginsenosides in hydroponically-cultivated ginseng leaf (A), fruit (B), and root (C). RT, retention time.

\section{The analysis of ginsenosides}

The content of ginsenosides was quantitatively analyzed with an HPLC system (Jasco, Tokyo, Japan). Us- ing a bondapak $\mathrm{C}_{18}$ column $(10 \mu \mathrm{m}, 3.9 \times 300 \mathrm{~mm})$, water (solvent A) and acetonitrile (solvent B) were mixed in $80 \%$ solvent $\mathrm{A}$ in the beginning of the analysis, then after 
A

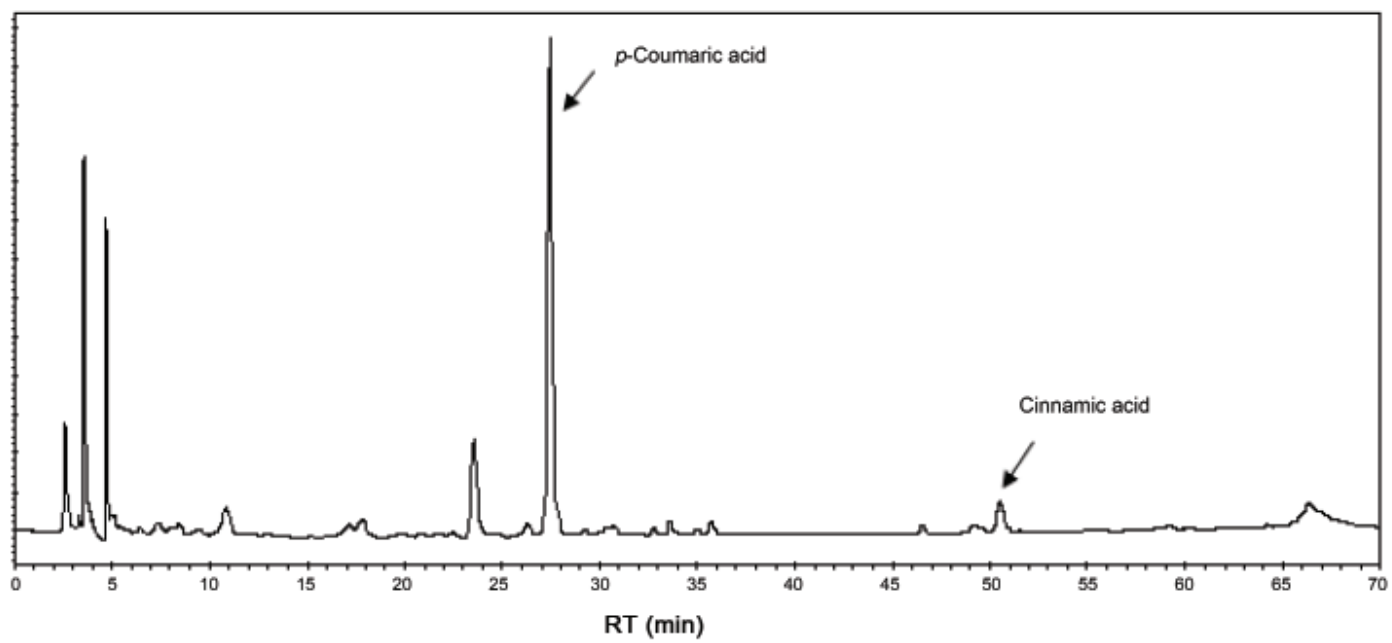

B

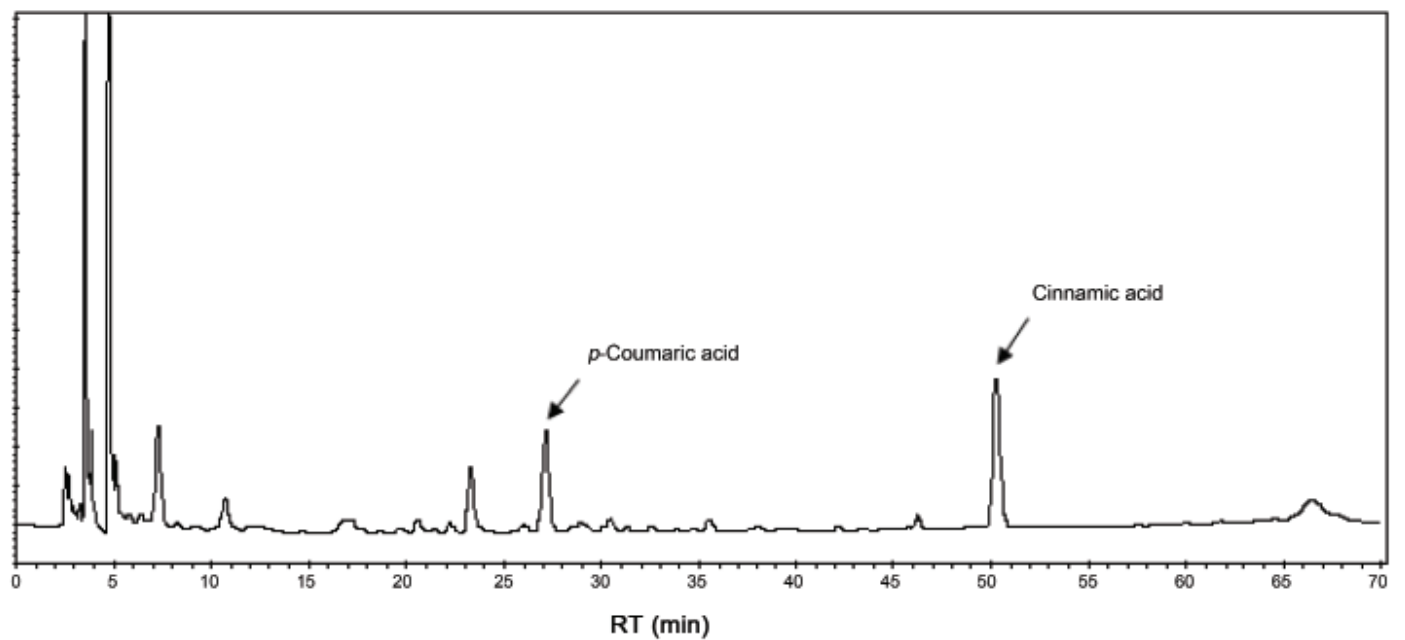

C

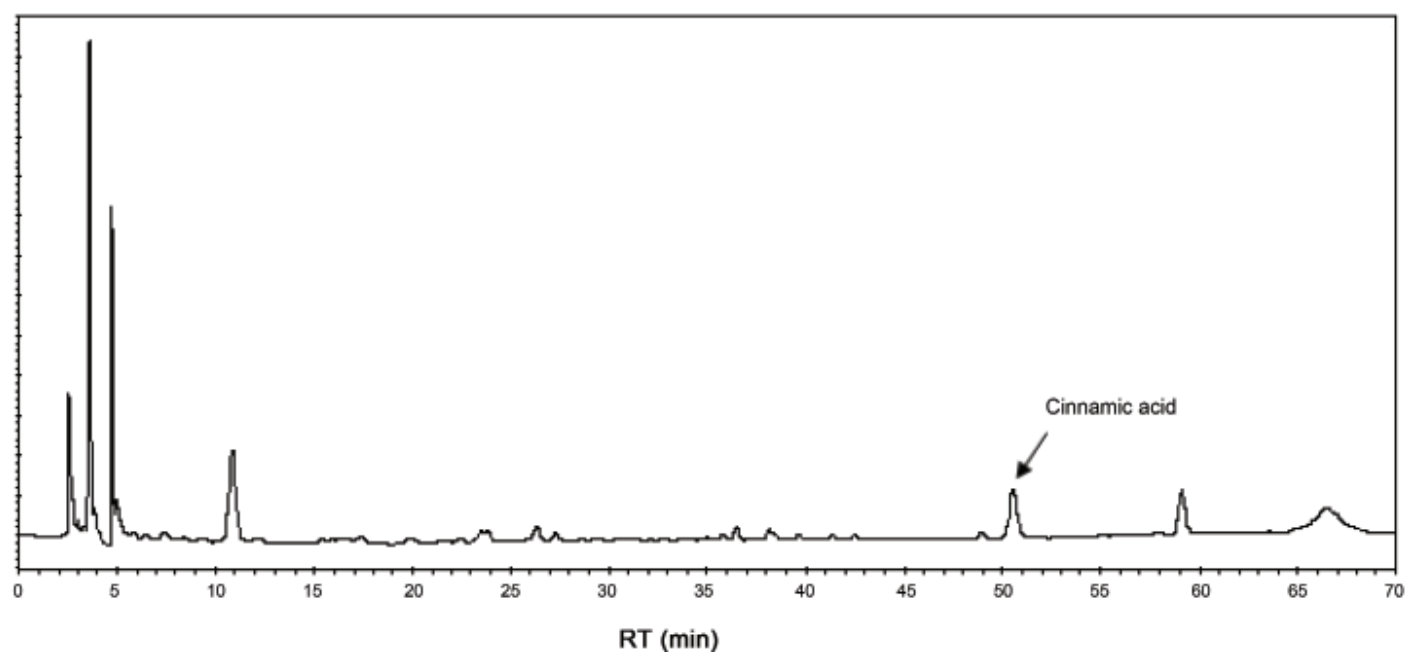

Fig. 2. Chromatogram of phenolic compounds in hydroponically-cultivated ginseng leaf (A), fruit (B), and root (C). RT, retention time.

70 min of the analysis, the solution was switched to a $0 \%$ solvent A by a gradient mobile phase. The elution speed was maintained at $1.0 \mathrm{~mL} / \mathrm{min}$, the temperature of the column was maintained at $25^{\circ} \mathrm{C}$, and the absorbance was 
Table 1. Ginsenoside composition of hydroponically-cultivated ginseng fruit, leaf, and root ethanol extracts (mg/g)

\begin{tabular}{ccccccccccccc}
\hline & $\mathrm{Rg} 1$ & $\mathrm{Re}$ & $\mathrm{Rf}$ & $\mathrm{Rg} 2+\mathrm{Rh} 1$ & $\mathrm{Rb} 1$ & $\mathrm{Rc}$ & $\mathrm{Rb} 2$ & $\mathrm{Rb} 3$ & $\mathrm{Rd}$ & $\mathrm{Rg} 3(\mathrm{~S}, \mathrm{R})$ & $\mathrm{Rh} 2$ \\
\hline Leaf & 36.2 & 61.3 & 0.6 & 17.4 & 3.1 & 6.1 & 5.2 & 0.5 & 38.0 & 2.2 & - \\
Fruit & 15.8 & 101.0 & 1.5 & 14.7 & 1.3 & 2.8 & 1.7 & 0.2 & 12.0 & - & - \\
Root & 19.4 & 54.9 & 7.0 & 6.3 & 29.2 & 31.8 & 18.7 & 3.0 & 12.7 & - & - \\
\hline
\end{tabular}

S, S form; R, R form.

measured at $203 \mathrm{~nm}$. To obtain specimens for analysis, the concentrated extracts were diluted with methanol to $10 \mathrm{mg} / \mathrm{mL}$ and filtered with a $0.45 \mu \mathrm{m}$ syringe filter (Millipore, Bedford, MA, USA) $[5,6]$.

\section{The analysis of phenolic compounds}

The contents of three phenolics (maltol, $p$-coumaric acid, and cinnamic acid) were measured with an HPLC system (Jasco, Tokyo, Japan). For quantitative analysis of the phenolic content using HPLC, $2 \%$ acetic acid-containing water (solvent $\mathrm{A}$ ) and $0.5 \%$ acetic acid-containing $50 \%$ acetonitrile (solvent B) were mixed in $100 \%$ solvent $\mathrm{A}$ in the beginning of the analysis, then after $70 \mathrm{~min}$ of the analysis, the solution was mixed in $45 \%$ solvent $\mathrm{A}$ by a gradient mobile phase, using a bondapak $\mathrm{C}_{18}$ column (4 $\mu \mathrm{m}, 3.9 \times 300 \mathrm{~mm}$ ). The elution speed was maintained at 0.8 $\mathrm{mL} / \mathrm{min}$, the temperature of the column was maintained at $40^{\circ} \mathrm{C}$, and the absorbance were measured at $280 \mathrm{~nm}$. To obtain specimens for analyses, the concentrated extracts were diluted with methanol to $10 \mathrm{mg} / \mathrm{mL}$, and filtered with a $0.45 \mu \mathrm{m}$ syringe filter (Millipore, Billerica, USA).

\section{2,2'-Azino-di-(3-ethylbenzothiazoline)-6-sulfonic acid scavenging effects}

2,2'-Azino-di-(3-ethylbenzothiazoline)-6-sulfonic acid (ABTS) radical scavenging activities were measured as described by Van den Berg et al. [7], with slight modifications. $2.5 \mathrm{mM}$ ABTS and $1.0 \mathrm{mM} \mathrm{2,2'-azobis(2-}$ methylpropionamidine) dihydrocholide was mixed in 0.1 $\mathrm{M}$ phosphate buffered saline (PBS, $\mathrm{pH}$ 7.4). The mixture was reacted in a darkroom at $68^{\circ} \mathrm{C}$ for $12 \mathrm{~min}$, then rapidly cooled to produce the $\mathrm{ABTS}^{+}$solution. Twenty microliter of the PBS-melted ginseng extract was added to $980 \mu \mathrm{L}$ of the $\mathrm{ABTS}^{+}$solution and incubated at $37^{\circ} \mathrm{C}$ for $10 \mathrm{~min}$, and the optical density of the solution was measured at $734 \mathrm{~nm}$.

\section{RESULTS AND DISCUSSION}

\section{Quantification of ginsendoside and phenolic in- gredient contents}

In the ginsenoside content analyses of hydroponically-
Table 2. Phenolic ingredient composition of hydroponically-cultivated ginseng fruit, leaf, and root ethanol extracts $(\mu \mathrm{g} / \mathrm{g})$

\begin{tabular}{cccc}
\hline & Matol & $p$-Coumaric acid & Cinnamic acid \\
\hline Fruit & - & 247.8 & 212.8 \\
Leaf & - & 965.9 & 46.4 \\
Root & - & 14.8 & 69.9 \\
\hline
\end{tabular}

cultivated ginseng plants, the roots were shown to contain high amounts of ginsenoside Rf, Rb1, Rc, Rb2, and $\mathrm{Rb3}$, whereas the fruits contained high amounts of ginsenoside $\operatorname{Re}(101.0 \mathrm{mg} / \mathrm{g}$ in ethanol extract). Compared to the other parts of the plants, the leaves contained higher amounts of gensenoside Rg1, Rg2+Rh1, Rd, and $\operatorname{Rg} 3$ (Table 1 and Fig. 1). These results were similar with those of other studies on soil-cultivated ginseng plants, which reported that soil-cultivated ginseng fruits contained particularly high amounts of ginsenoside Re [8], and soil-cultivated ginseng leaves contained high amounts of ginsenoside Rg1, Re, and Rd [9]. Accordingly, there was no difference between soil-cultivated ginseng leaves and hydroponically-cultivated ginseng leaves in terms of ginsenoside composition.

Based on the quantitative analysis of the phenolic contents, hydroponically-cultivated ginseng leaves were shown to contain high amounts of $p$-coumaric acid (965.9 $\mu \mathrm{g} / \mathrm{g}$ in ethanol extract), whereas the fruits contained high amounts of cinnamic acid (Table 2 and Fig. 2). In a study by Lee et al. [10], even though a different extraction solution was used, soil-cultivated ginseng leaves were reported to contain higher amounts of cinnamic acid than $p$ coumaric acid. However, the result of this study showed that hydroponically-cultivated ginseng leaves contained significantly higher amounts of $p$-coumaric acid.

\section{Radical scavenging effects}

Based on the ABTS radical scavenging activities of ethanol extracts from hydroponically-cultivated ginseng plants, the leaves were shown to display an activity of $76.7 \%$ at $100 \mu \mathrm{g} / \mathrm{g}$, whereas the activity of the fruits and roots were $39.5 \%$ and $53.2 \%$, respectively (Fig. 3). These results demonstrated that the leaves showed the highest 


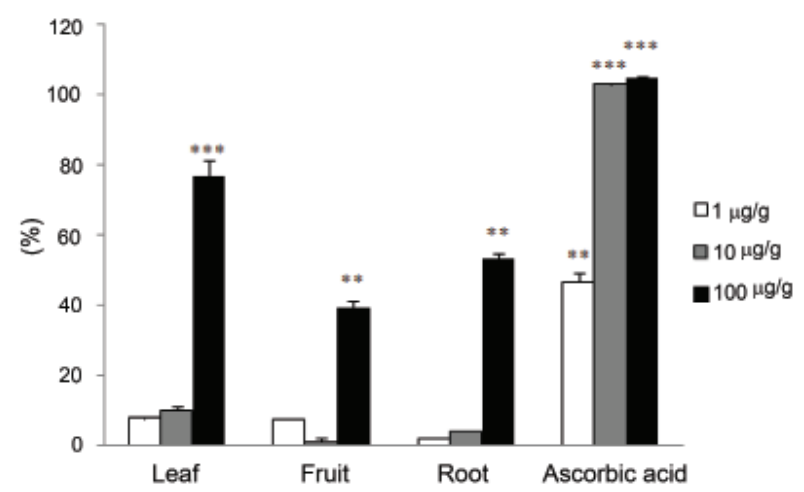

Fig. 3. 2,2'-Azino-di-(3-ethylbenzothiazoline)-6-sulfonic acid radical scavenging activity of the ginseng ethanol extracts of leaf, fruit, and root. Data are expressed as mean \pm SD of three experiments. Ascorbic acid was used as a positive control. ${ }^{* *} p<0.01,{ }^{* * *} p<0.001$.

free radical scavenging activity. The results of a study by Nenadis et al. [11] showed that $p$-coumaric acid most effectively eliminated ABTS among the 11 cinnamic acid derivatives. The $p$-coumaric acid content, which was present in high concentrations in hydroponically-cultivated ginseng leaves, seemed to be the major substance responsible for the ABTS radical scavenging activity. These results imply that hydroponically-cultivated ginseng leaves hold promise for use as an environmentallyfriendly anti-oxidant.

\section{REFERENCES}

1. Park JD. Recent studies on the chemical constituents of Korean ginseng (Panax ginseng C.A. Meyer). Korean J Ginseng Sci 1996;20:389-415.

2. Lee DY, Cho JG, Lee MK, Lee JW, Lee YH, Yang DC, Baek NI. Discrimination of Panax ginseng roots cultivated in different areas in Korea using HPLC-ELSD and principal component analysis. J Ginseng Res 2011;35:3138.
3. Kim HD, Ha SE, Kang JR, Park JK. Effect of Korean red ginseng extract on cell death responses in peroxynitritetreated keratinocytes. J Ginseng Res 2010;34:205-211.

4. Baek SH, Bae ON, Park JH. Recent methodology in ginseng analysis. J Ginseng Res 2012;36:119-134.

5. Hong HD, Sim EM, Kim KT, Rho JH, Rhee YK, Cho $\mathrm{CW}$. Comparison of preparation methods for the quantification of ginsenosides in raw Korean ginseng. Food Sci Biotechnol 2009;18:565-569.

6. Hong HD, Choi SY, Kim YC, Lee YC, Cho CW. Rapid determination of ginsenosides Rb1, Rf, and Rg1 in Korean ginseng using HPLC. J Ginseng Res 2009;33:8-12.

7. Van den Berg R, Haenen GR, Van den Berg H, Bast A. Applicability of an improved Trolox equivalent antioxidant capacity (TEAC) assay for evaluation of antioxidant capacity measurements of mixtures. Food Chem 1999; 66:511-517.

8. Yeom MH, Lee JY, Kim JS, Park CW, Kim DH, Kim HK. The anti-aging effects of Korean ginseng berry in the skin. Korean J Pharmacogn 2010;41:26-30.

9. Kim YK, Yoo DS, Xu H, Park NI, Kim HH, Choi JE, Park SU. Ginsenoside content of berries and roots of three typical Korean ginseng (Panax ginseng) cultivars. Nat Prod Commun 2009;4:903-906.

10. Lee KS, Seong BJ, Kim GH, Kim SI, Han SH, Kim HH, Baik ND. Ginsenoside, phenolic acid composition and physiological significances of fermented ginseng leaf. $\mathrm{J}$ Korean Soc Food Sci Nutr 2010;39:1194-1200.

11. Nenadis N, Wang LF, Tsimidou M, Zhang HY. Estimation of scavenging activity of phenolic compounds using the ABTS(*+) assay. J Agric Food Chem 2004;52:46694674. 